\title{
LONG-TERM MONITORING OF A DEEP-SEATED, SLOW-MOVING LANDSLIDE BY MEAN OF C-BAND AND X-BAND ADVANCED INTERFEROMETRIC PRODUCTS: THE CORVARA IN BADIA CASE STUDY (DOLOMITES, ITALY).
}

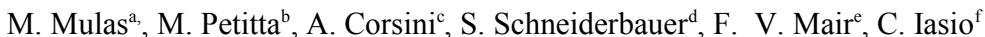

\begin{abstract}
${ }^{a}$ Università di Modena e Reggio Emilia (UniMoRe), Chemistry and Earth Science Department, L.go S. Eufemia 19, 41121 Modena, Italy, European Academy of Bolzano (Eurac), Institute for Applied Remote Sensing, Bolzano, Italy - marco.mulas@unimore.it;

${ }^{\mathrm{b}}$ European Academy of Bolzano (Eurac), Institute for Applied Remote Sensing, Bolzano, Italy - marcello.petitta@eurac.edu;

${ }^{c}$ Università di Modena e Reggio Emilia (UniMoRe), Chemistry and Earth Science Department, Modena, Italy alessandro.corsini@unimore.it;

d European Academy of Bolzano (Eurac), Institute for Applied Remote Sensing, Bolzano, Italy - stefan.schneiderbauer@eurac.edu; e Autonomous Province of Bolzano: Geological Surveys and building material test Office, Cardano, Italy volkmar.mair@provincia.bz.it;

f Henesis srl, Camlin Group, Viale dei Mille 108, 43125 Parma - christian.iasio@henesis.eu
\end{abstract}

KEY WORDS: Deep-seated landslide, Monitoring, SAR, Advanced-Interferometry, Time-Series, Landslides

\begin{abstract}
:
The availability of data from various Synthetic Aperture Radar (SAR) operating in X-Band and C-Band acquired in the last decades enables to monitor slopes affected by landslides. The ASI-founded project 'LAWINA' $(2010-2012)$ aimed at the improvement of SAR - based monitoring techniques as well as at the integration of SAR data with data stemming from other sensors. Test case area of LAWINA has been a slow-moving landslide located up-stream of Corvara in Badia village in the Dolomites, Italy. Within the scope of the project different time-series obtained through 35 Envisat2, 40 Radarsat-1 and 46 Cosmo-SkyMed covering this test area have been processed in order to explore the potentials to analyse historical and near real time landslide dynamics. The SAR data are characterized by various geometric and temporal resolutions having been acquired by 3 sensors operating at different bands in different periods between 2003 and 2011. TeleRilevamento Europa (TRE) exploited these data in order to retrive displacement timeseries applying its proprietary SqueeSAR algorithm. After re-projecting Envisat-2 and Radarsat datasets according to the CSK Line Of Sight a comparison of displacements recorded by each sensor has been possible. For this purpose, we have selected areas characterized by the presence of Persistent Scatterers or Diffused Scatterers from at least two datasets. This multi-sensor approach allowed determining the slope displacement tracking during 8 years. Even though the different time series are not formally integrated each other, the result is accurate enough to allow the evaluation of the landslide's behaviour and trend over several years.
\end{abstract}

\section{INTRODUCTION}

This work presents results derived from datasets and elaborations of the LAWINA project, founded by the $1^{\text {st }}$ Announcement for Opportunities for civil application of Cosmo-SkyMed ${ }^{\circledR}\left(\mathrm{CSK}^{\circledast}\right)$ constellation. The availability of three datasets acquired by Envisat2, Radarsat-1 and CSK satellites in different periods between 2003 and 2011 allowed slope displacement tracking along the area of Corvara in Badia located in the Dolomites (Bolzano Province, Italy).

\section{CASE STUDY}

\subsection{Landslide description}

The area of study covers the Corvara Landslide a deep-seated phenomenon classified by Corsini et al.(1999) as an active, slow moving, rotational earth slide - earth flow with a complex style of movement. The total mobilized volume has been estimated to be about 50 million $\mathrm{m}^{3}$ with an average depth of the shear surface of $30-35 \mathrm{~m}$ and an active surface of $1.3 \mathrm{~km}^{2}$ (Corsini et al., 2005). The body of the Corvara Landslide partially covers the "Arlara" paleo-landslide that was active

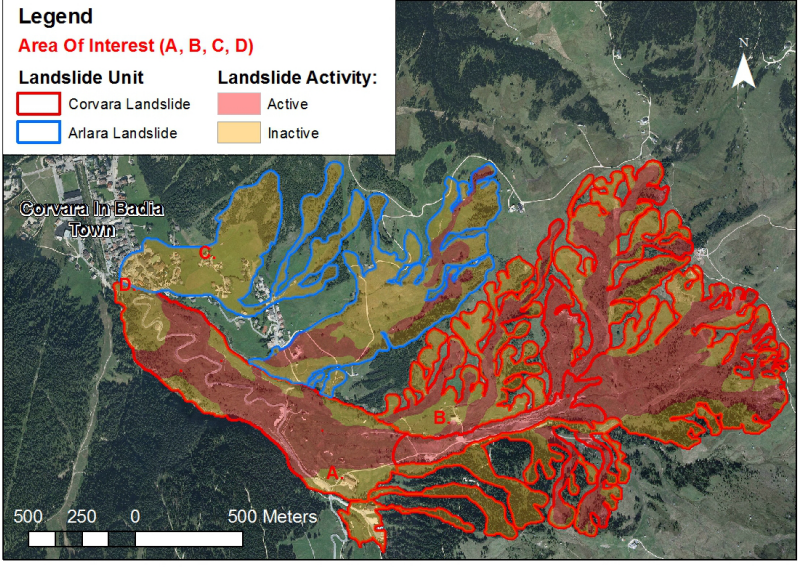

Figure 1. Map of the investigated area 


\section{3. .METHODOLOGY}

\subsection{Dataset}

The elaborated dataset consists in acquisitions obtained from three different SAR satellites operating in $\mathrm{C}$ and $\mathrm{X}$ band elaborated by TRE using their proprietary algorithm SqueeSAR for advanced multi-interferometric analysis (Ferretti at al., 2011).

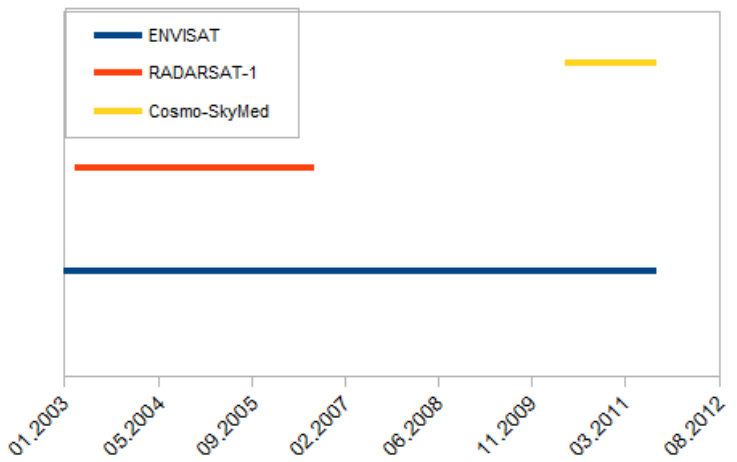

Figure 2: Dataset time-line

The C-band datasets are composed of 35 ENVISAT acquisitions taken from January 2003 to September 2010 with a mean granularity of 70 days and 40 RADARSAT- 1 acquisitions covering the period from March 2003 to September 2006 with a temporal resolution of 24 days. The Cosmo-SkyMed dataset is referred to the period from May 2010 to September 2011 with a mean granularity of 16 days (see table 3 for more informations).

\begin{tabular}{|l|c|c|c|}
\hline & Radarsat-1 & $\begin{array}{c}\text { Cosmo- } \\
\text { SkyMed }\end{array}$ & Envisat \\
\hline $\begin{array}{l}\text { Acquisition } \\
\text { mode } \\
\text { Orbit }\end{array}$ & Standard S3 & $\begin{array}{c}\text { Stripmap } \\
\text { Himage } \\
\text { Descending }\end{array}$ & $\begin{array}{c}\text { Narrow Swath } \\
\text { S2 } \\
\text { Descending }\end{array}$ \\
$\begin{array}{l}\text { Incidence } \\
\text { angle }\end{array}$ & $34.05^{\circ}$ & $45.77^{\circ}$ & $24.27^{\circ}$ \\
$\begin{array}{l}\text { Polarization } \\
\begin{array}{l}\text { Temporal } \\
\text { resolution* } \\
\text { Spatial } \\
\text { resolution }\end{array}\end{array}$ & 24 days & 16 days & 70 days \\
\hline
\end{tabular}

Table 3. Dataset characteristics (*mean value)

\subsection{Comparison of displacements}

In order to achieve the comparison of time-series recorded by mean of different SAR satellites the resulting displacements from the SqueeSAR elaboration have been projected along the Cosmo-Skymed Line Of Sight (LOS). Table 4 are presents the satellite unit vectors for each sensor.

$$
d_{L O S}=\vec{S} * D
$$

where: $\quad \mathrm{d}_{\mathrm{LOS}}=$ computed displacement along

Line Of Sight

$\mathrm{D}=$ surface displacement

$\mathrm{s}=$ satellite unit vector

\begin{tabular}{|l|c|c|c|}
\hline $\begin{array}{l}\text { Satellite unit } \\
\text { vector }\end{array}$ & Radarsat-1 & $\begin{array}{c}\text { Cosmo- } \\
\text { SkyMed }\end{array}$ & Envisat \\
\hline $\mathbf{S}_{\text {est }}$ & 0.55 & 0.71 & 0.40 \\
$\mathbf{S}_{\text {nord }}$ & -0.09 & -0.08 & -0.07 \\
$\mathbf{S}_{\text {height }}$ & 0.83 & 0.70 & 0.91 \\
\hline
\end{tabular}

Table 4. Line of Sight Parameters

A selection of clusters of points have been made looking for areas where Permanent Scatterer (PS) or Distributed Scatterer (DS) detected by at least by two sensors were present. For these clusters, each one identifying an Area Of Interest, PS and DS time-series have been re-aligned and plotted together in order to compare the information derived from different platforms.

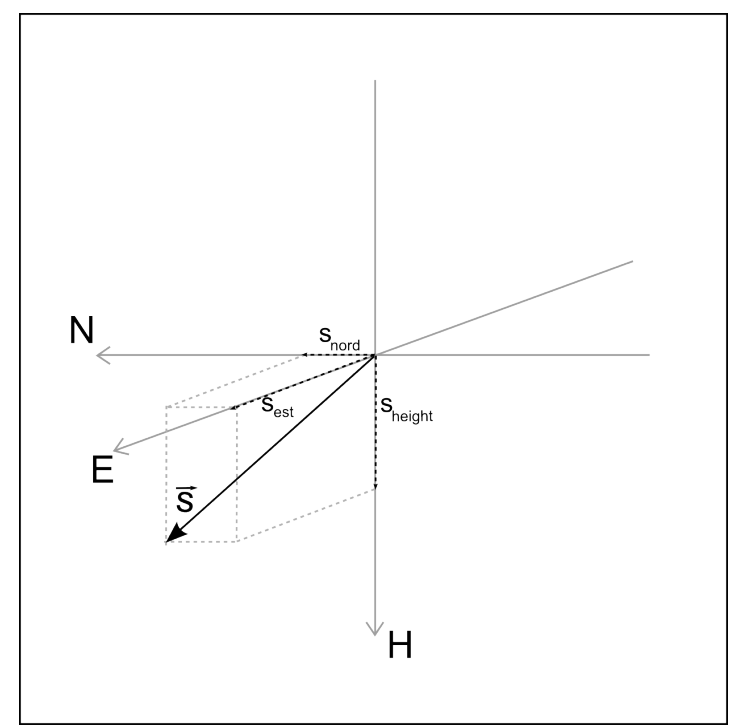

Figure 5: Satellite unit vector representation

\section{RESULTS}

A total of 4 Areas of Interest (AOI) characterised by the presence of multi-source PS/DS have been localised (figure 1 and 6). Those AOI are located in the inactive zones of the Corvara Landslide (A and D), in the body of the Arlara paleolandslide $(\mathrm{C})$ and in the track zone of the Corvara Landslide (B).

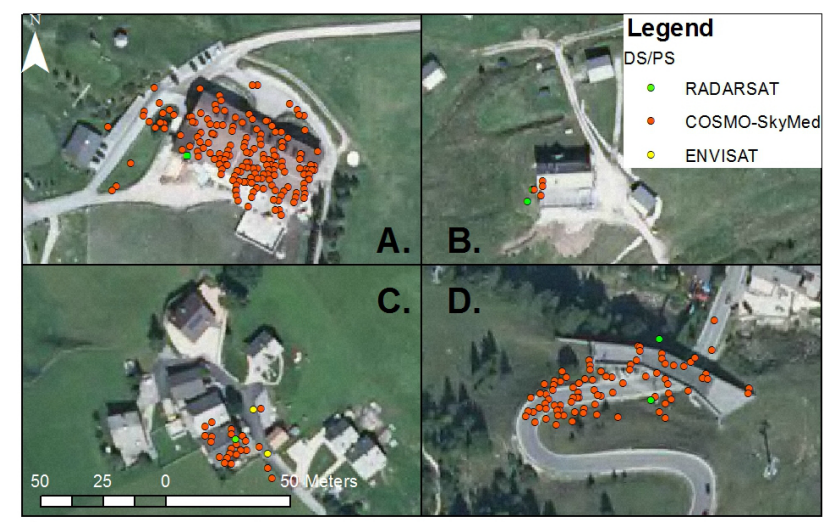

Figure 6: Locations with multiple sensor measurements. 
In the AOI A both time-series obtained from Cosmo-SkyMed and Radarsat acquisitions show a horizontal trend confirming the inactivity of this portion of landslide (figure 7). From this analysis emerges that this area has not been in movement since 2003.

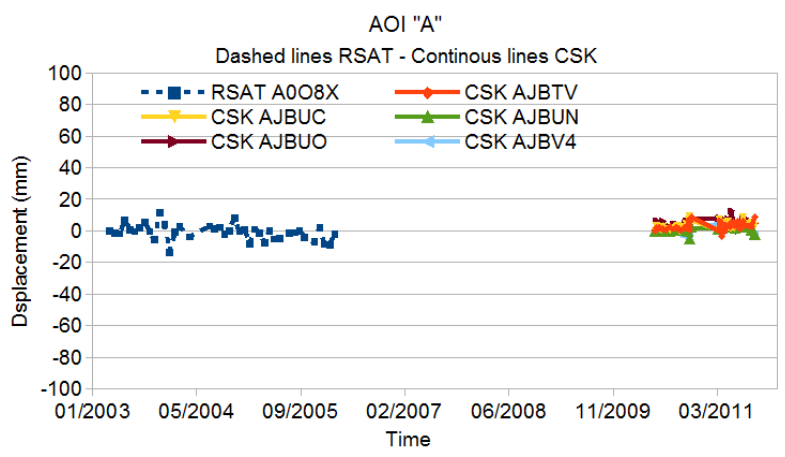

Figure 7: Displacement recorded in the AOI "A" using Cosmo-SkyMed and Radarsat satellites

Data located in AOI "D" give information about the stability of the toe of the Corvara Landslide in the period from September 2002 to April 2012 (figure 8). This AOI is characterised by the temporal overlapping of time-series showing a coherent information

$\mathrm{AOI}$ "D"

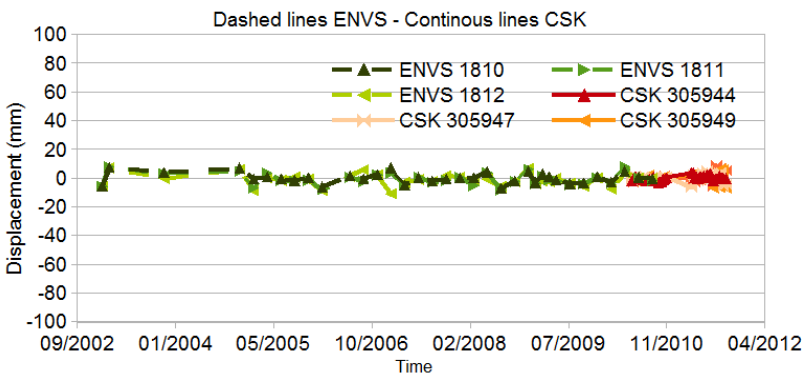

Figure 8: Displacement recorded in the AOI "D" using Cosmo-SkyMed and Envisat satellites

The Arlara paleo-landslide, where are located PS/DS belonging to AOI "C", confirms its inactivity by stability of monitoring points derived from all three the sensors (figure 9). The information for this AOI reveals that at least starting from January 2003 up to April 2011 the paleo-landslide has not been active.

$\mathrm{AOI}$ "C"

Dashed lines RSAT - Continous lines ENVS - Dashed-dotted lines CSK

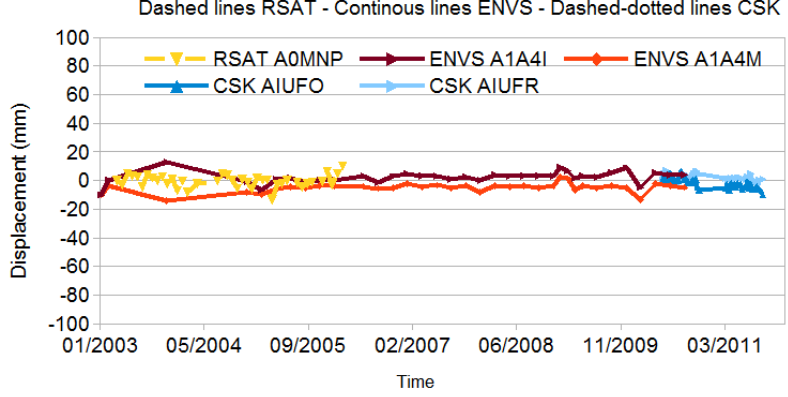

Figure 9: Displacement recorded in the AOI "C" using Cosmo-SkyMed. Radarsat and Envisat satellites
Points of the AOI "B" (figure 10), located in the margins of the track zone of the Corvara Landslide, confirm the activity of this portion of landslide represented by a total displacement of 20 centimetres and a mean velocity of $2,45 \mathrm{~cm} /$ year.

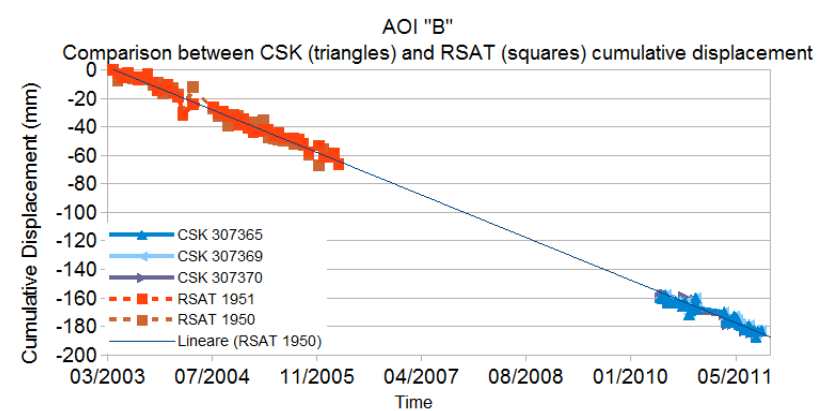

Figure 10: Displacement recorded in the AOI "B" using Cosmo-SkyMed and Radarsat satellites

\section{CONCLUSIONS}

The integrated use of time-series derived from the multiinterferometric elaboration of acquisitions obtained from different Synthetic Aperture Radar satellites have shown its potential in this work. This type of application shows how to integrate different data in order to confirm field hypothesis about the evolution of a slope during almost a decade. Despite the scarce presence of Persistent and Diffused Scatterers in the whole study area we have identified 4 clusters of points characterised by PS/DS obtained at least from two sensors describing the evolution of those areas in time.

The use of archive of multiple SAR missions acquired in areas characterised by a good radiometric coherence (inhabited areas, presence of anthropic infrastructures or outcropping rocks) would give better results with a higer number of measured points (PS/DS). This study has shown how a post-elaboration of multi-interferometric results helps in improving the information about the stability/instability of slopes throughout years by means of several satellite SAR missions.

\section{REFERENCES}

Corsini, A., Pasuto, A., Soldati, M., 1999. Geomorphological investigation and management of the Corvara landslide (Dolomites, Italy). Transactions-Japanese Geomorphological Union 20, 169-186.

Corsini, A., Marchetti, M., Soldati, M., 2001. Holocene slope dynamics in the area of Corvara in Badia (Dolomites, Italy). Geografia Fisica e Dinamica Quaternaria 24, 127-139.

Corsini, A., Pasuto, A., Soldati, M., Zannoni, A., 2005. Field monitoring of the Corvara landslide (Dolomites, Italy) and its relevance for hazard assessment. Geomorphology 66, 149-165. doi:10.1016/j.geomorph.2004.09.012

Ferretti, A., Fumagalli, A., Novali, F., Prati, C., Rocca, F., Rucci, A., 2011. A New Algorithm for Processing Interferometric Data-Stacks: SqueeSAR. IEEE Trans. Geosci. Remote Sens. 49, 3460-3470. 